\title{
Nueva definición de "vida": La "vida" es una reacción en cadena que acumula anti-entropía
}

\author{
Luis Bertrand Arbaiza Escalante \\ dnarb9000@yahoo.com \\ Luis Piscoya Hermosa \\ lpiscoya@gmail.com
}

\section{Resumen}

Carecemos de una definición de "vida" satisfactoria, por ello se propone una nueva basada en una hipótesis: La "vida" es una reacción en cadena que acumula anti-entropía. De este axioma se pueden inferir las siguientes consecuencias: Se caracteriza la vida como un fenómeno físico; No hay contra-ejemplos ni individuos intermedios; La anti-entropía acumulada es causalidad material cuyo efecto prolonga la reacción en cadena; Puede haber vida sin células; los virus son vida, los priones no; La vida terrestre empezó con el primer ARN; El proceso de acumulación de anti-entropía es abiótico, la evolución es un caso particular de esto; Reconocer vida extraterrestre no implica el análisis de individuos sino de sus relaciones; La vida puede existir en otras conformaciones de la materia y las especies de reproducción exclusivamente asexual no son vida.

Palabras clave: vida, Epistemología, Exobiología.

\section{Abstract}

We lack of a satisfactory definition of "life", for which one is proposed based on one hipótesis: "Life" is a chain reaction that accumulates anti-entropy. From this axiom the following consequences can be inferred: Life is characterized as a physical phenomenon; There are no counter-examples or intermediate individuals; The accumulated anti-entropy is material causality whose effect prolongs the chain reaction; There can be life without cells; Viruses are life, prions are not; Terrestrial life began with the first RNA; The process of accumulation of anti-entropy is abiotic, evolution is particular case of this; Recognizing extraterrestrial life does not imply the analysis of individuals but their relationships: Life can exist in other conformations of matter and the exclusively asexual reproduction species are not life.

Key words: life, Epistemology, Exobiology. 


\section{Nueva definición de "vida": \\ La "vida" es una reacción en cadena \\ que acumula anti-entropía}

\section{Introducción}

La acepción de "vida" analizada corresponde al tema del que trata la biología. No al periodo de tiempo de un organismo, ni a lo opuesto a la muerte ni a la existencia consciente que tienen algunos organismos, o a aquello que perdemos al morir.

\section{1 ¿Qué es la vida? problema filosófico, no biológico}

Lo que es o no es la vida, debe decirse desde afuera de la biología, pues lo que esta ciencia es, depende de esa definición. Definir la "vida" concierne a la epistemología y más precisamente a la filosofía de la biología. Para Bunge es un problema ontológico-biológico (Bunge, 2000). Para Rinaldi no es un asunto científico:

They point to the key problem that experimental evidence-at least, for extraterrestrial life-is difficult, if not impossible, to obtain, thus making it a speculative rather than an observational science (Rinaldi, 2007, p. 436)

Para Claus Emmeche es un problema semiótico:

As a notion or general idea of life it is seen as a member of a set of definitions bordering science proper and philosophy of nature, here called ontodefinitions. [...] Defining life as biosemiotic processes seems to imply the emergence of functionality as a kind of 'biological meaning' in the physical world. (Emmeche, 1998, p. 3) 


\subsection{Problema general: Falta de definición}

En la actualidad no se ha resuelto la definición del concepto de "vida". Aún está en discusión si los virus son seres vivos. Algunos filósofos de la biología planten incluso no resolver el problema sino disolverlo, por ejemplo Bunge anota:

Más aun la biología molecular y en particular las teorías de evolución molecular parecen incluso haberse desanimado en una definición de vida, basándose en que no tendría sentido trazar una distinción nítida entre entidades vivas y no vivas: habría una transición continua y gradual. (Bunge, 2000, p. 165)

Otros autores señalan que no hay una definición consensuada y suficiente (Smith, 2016; Tirard, 2010; Cleland, 2010; Regis, 2009).

Sin duda existe una intuición de lo que es "vida". Pero ¿existe algo en el mundo natural realmente agrupe lo que intuimos como "vida"?

\section{3 ¿Definir Vida o ser vivo?}

Acaso los "seres vivos" (y no la "vida") sean los únicos sujetos de análisis científico y epistemológico. Y la "vida" sea una abstracción más propia de la metafísica por su ambigüedad y falta de independencia de los fenómenos concretos y reales. Al modo de que Tarski que solo define las proposiciones verdaderas no la verdad. Bunge argumenta algo análogo:

Un problema concerniente a un trozo de la realidad de manera científica presupone que está tratando con algo real, con alguna cosa real y concreta por lo menos supuestamente, hipotéticamente real, dotado entonces de propiedades relacionadas entre sí por leyes. Así por ejemplo el físico no estudia "el movimiento", ya lo advirtió Aristóteles, el físico estudia cosas que se mueven no el movimiento en sí, el químico no estudia reacciones químicas, estudia las reacciones entre compuestos, el biólogo no estudia bio-funciones en sí mismas, sino procesos... (Ininteligible), y trata con cosas en procesos de cambio. (Bunge, 1980)

¿Es acaso la búsqueda de la "vida" una búsqueda metafísica? ¿Deberíamos satisfacernos con definir ser vivo?

\section{4 ¿Cómo definirla científicamente?}

Hay una serie de requisitos formales y materiales que debe satisfacer una definición para ser científica. La definición vida también debe satisfacerlos. Los criterios han sido bien definidos por Mosterin (2000) y por Hempel (1987). Pueden resumirse así: 


\section{Formales}

1.-Permiten hacer explicaciones, predicciones y retrodicciones.

2.-Pueden ser descriptivas. Que sirven para describir el significado de un término ya en uso. En ellas el definiendum, se explica por el definiens, es decir con términos ya definidos que pueden sustituirlo. Son denominadas definiciones descriptivas analíticas. falsas.

3.- Se puede decir que son más o menos exactas, o incluso verdaderas o

4.- Se debe evitar "círculos", que definen un término con ayuda de sí mismo.

5.- Las definiciones son particiones en sentido matemático, clasificaciones no-solapantes. O sea generan clases de individuos. Ningún individuo debe pertenecer a dos conceptos clasificatorios y debe pertenecer a algún concepto de clasificación.

6.-En definiciones operacionales el significado de un término científico indica una operación definida de contrastación.

\section{Materiales}

7.- Una partición es más fina que otra cuando hace todas las distinciones que esta y algunas más.

\subsection{Problemas secundarios}

Una serie de problemas de la biología están en suspenso por no tener definición de "vida" por ejemplo:

-¿Los virus y/o priones son seres vivos?

- ¿Cómo empezó la vida en la tierra?

-¿Cómo reconocer vida extraterrestre o sintética?

\section{Antecedentes}

Los autores analizados a continuación, a diferencia de esta tesis, han definido vida como algo en cada organismo. En todos los casos esto ha llevado a contradicciones.

\subsection{Aristóteles 1: Vida como algo que puede reproducirse}

Aristóteles que define vida como "algo que deja tras de sí un ser semejante a él” (Aristóteles, 2007). Pero Aristóteles describe así, reacciones en cadena y lo 
malo de definirla así es que contiene a los seres vivos, pero además contiene otras cosas no vivas como la fusión de uranio o el fuego.

\subsection{Aristóteles 2 Automovimiento}

En De Anima Aristóteles señala a la vida como automovimiento, explica que unas cosas son movidas por algo exterior (inanimadas) y otras por algo interior, estas son las animadas; esta definición alude a la voluntad. Hay que recordar que Aristóteles se refería a los animales y no a las plantas u otras formar de vida. Este es un concepto naif de vida, de hecho los animales y los niños pueden distinguir a los seres vivos de los inertes con este criterio. Es un concepto primitivo y eficiente, pero solo en nivel macroscópico. Las leyes del movimiento de Newton refutan esta visión al mostrar que un objeto puede estar en movimiento sin tener que ser movido por otro (movimiento inercial), lo que convertiría en un ser vivo a un cometa, a un robot o a un juguete a pilas. $Y$ dado que todo objeto que está a una temperatura mayor al 0 absoluto se mueve sin ser movido por otra cosa, todo sería vida.

\subsection{Erwin Schrödinger 1944}

Para este autor los sistemas vivos son una organización de la materia donde se produce un continuo incremento de orden sin intervención externa (Schrödinger, 1944). El problema es que varios objetos no vivos pueden incrementar su anti-entropía u orden, un ejemplo es la formación de cristales donde las moléculas se ordenan. Otro problema es que Schrödinger se refiere a sistemas termodinámicos cerrados, pero los sistemas vivos son abiertos.

\subsection{Maturana: Autopoiesis}

\section{Para Maturana}

La Autopoiesis es un sistema capaz de reproducirse y mantenerse por sí mismo, una máquina organizada como una red de procesos de producción que a través de sus interacciones y transformaciones continuamente regeneran y realizan la red de procesos que los han producido, y la constituyen (la máquina) como una unidad concreta en el espacio en el que ellos (los componentes) existen especificando el dominio topológico de su realización como tal de una red". (Maturana y Varela, 1973, p, 68)

Pero su definición falla al ser simplemente la definición de una reacción en cadena (dicho en difícil) y la homeostasis. Nuevamente convertiría a todas las reacciones en cadena en formas de vida. Como señala Bunge el termino 
Autopoiesis es "un sinónimo extravagante e inútil de homeostasis o auto-organización” (2000).

\subsection{Bunge: Biosistemas}

Para Bunge la vida es la colección de seres vivientes. Bunge admite que su definición solo abarca la vida en la tierra y no es extrapolable a una hipotética vida extraterrestre, con lo que resulta limitada. Admite además que no todas las propiedades de la vida pueden estar presentes en el ser vivo. Tampoco la capacidad de evolucionar es necesaria a sus biosistemas y que seres vivos solo pueden ser células y nada más pequeño. Por ello opina no debe existir el termino biología molecular. (Bunge y Hahner, 2000). Señala una lista extensiva de individuos y no una formula compresiva que denote al conjunto. Definir vida como colección de seres con vida implica un razonamiento circular. Su teoría requiere de células y eso dificulta comprender el origen de la vida, dado que estas ya son entes muy complejos y no se puede definir célula sin definir vida. Al no señalar que características son esenciales y proponer que algunos ser vivos podrían tener algunas características y otras no, su teoría se hace imprecisa e infalseable científicamente.

\subsection{NASA}

Para la NASA y la exobiología "vida es un sistema químico auto sostenible capaz de experimentar una evolución darwiniana” (Benner y Carrigan, 2004). La última parte (evolución darwiniana) lleva a un círculo vicioso pues solo se aplica a seres vivos (poblaciones y genes). Además la misma vida en la tierra evoluciona de otros modos además del darwiniano como por ejemplo el neutralismo, la epigenética y la evolución molecular.

\section{Objetivo}

Definir vida. Crear una definición fundamental del que deriven todas las características de la vida (teoremas) y que conforme un conjunto que englobe a todos los seres vivos y excluya a los inertes sin excepciones ni estados transicionales.

\section{Resultado: Hipótesis general}

4.1 AXIOMA 1: La "vida" es una reacción en cadena que acumula anti-entropía
$\mathrm{Ax}_{1}: \quad \forall(\mathrm{x})\{\mathrm{Vx}$
$\leftrightarrow$
$(\mathrm{Rx} \wedge \mathrm{Ax})\}$
Definiendum
Definiens 
Interpretación semántica de Ax1:

$\mathrm{V}(\mathrm{x})=\mathrm{df} \mathrm{x}$ es vida

$\mathrm{R}(\mathrm{x})=\mathrm{df}$ es una reacción en cadena

$\mathrm{A}(\mathrm{x})=\mathrm{df}$ acumula anti-entropía

Para todo proceso $\mathrm{x}$, si $\mathrm{x}$ es una reacción en cadena $(\mathrm{R})$ y $\mathrm{x}$ acumula anti-entropía (A), entonces el proceso $x$ es vida.

Dominio: vida

TEORÍA DE CONJUNTOS para el axioma 1

Conjunto $V=\{\forall(\mathrm{x}) \mid \mathrm{R}(\mathrm{x}) \wedge \mathrm{A}(\mathrm{x})\}$

Dado el conjunto $\mathrm{V}$ (“vida") reúne los elementos que tienen los predicados $\mathrm{R}$ y $\mathrm{A}$

Definiciones de predicados

Definiendum $=$ dfDefiniens

$\mathrm{R}(\mathrm{x})=\mathrm{x}$ es una reacción en cadena

$\mathrm{A}(\mathrm{x})=\mathrm{x}$ acumula anti-entropía

Se cumple el principio de discernibles

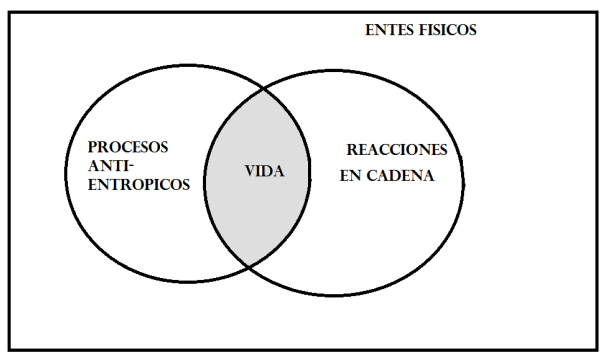

Figura 1. Vida es la intersección de 2 grupos de procesos físicos.

La vida entonces es un particular proceso físico con

estas 2 propiedades. Fuente: Elaboración propia.

\subsubsection{Predicado 1: Reacción en cadena}

Una reacción en cadena es una secuencia de reacciones físicas o químicas donde el producto de la reacción causa reacciones adicionales similares a las que le dio origen. Todas consumen energía.

\begin{tabular}{|l|l|}
\hline Reacción en cadena & \multicolumn{1}{c|}{ Fuete de energía } \\
\hline Fuego & Desorden de hidrocarburos. \\
\hline Uranio & Energía del cambio de materia a energía. \\
\hline Ozono & Rayos cósmicos. \\
\hline
\end{tabular}

Figura 2. Reacciones en cadena y sus fuentes de energía. Fuente: Elaboración propia. 


\subsubsection{Predicado 2: Acumulación de Anti-Entropía}

Entropía es una medida de desorden o caos en un sistema físico. Según Schrödinger:

At the absolute zero point of temperature (roughly $-273^{\circ} \mathrm{C}$ ) the entropy of any substance is zero ...the entropy increases by an amount which is computed by dividing every little portion of heat you had to supply in that procedure by the absolute temperature at which it was supplied and by summing up all these small contributions...You see from this, that the unit in which entropy is measured is cal./C. (Schrödinger, 1944, p. 25)

Formalmente se define así:

$$
\text { Entropía }=\mathrm{k} \log \mathrm{D}
$$

Donde k es la constante de Boltzmann (3.2983. 10-24 cal./C) y D la medida de desorden.

La anti-entropía es entropía inversa. Significa que las cosas se vuelven más ordenadas. Por orden se entiende organización y estructura. Su unidad es el J $\mathrm{kg}^{-1} \mathrm{~K}^{-1}$ (unidad de masa), y K $\mathrm{K}^{-1}$ (unidad de energía).

$$
\begin{gathered}
\text { 1/D es medida de orden } \\
\text { Logaritmo de } 1 / \mathrm{D} \\
\text {-(entropía })=\mathrm{k} \log (1 / \mathrm{D}) .
\end{gathered}
$$

El aumento de anti-entropía es pues la acumulación de anti-entropía y significa el aumento de orden o la reducción progresiva de caos en un sistema.

\section{Dos tipos de Anti-entropía: En los organismos y en la Vida}

Es necesario distinguir dos casos de aumento de anti-entropía:

1.-Aumento de anti-entropía en un individuo. A partir de una célula se acumula complejidad y luego se mantiene (homeostasia). Ha sido tratado por Schrödinger: "What an organism feeds upon is negative entropy" (1944, p. 25) y ya ha sido dilucidado por la bioquímica moderna y no es motivo de esta tesis.

\section{$\mathrm{Y}$}

2.- Aumento de anti-entropía en una reacción en cadena de individuos. En la "vida", el orden va apareciendo, conservándose y acumulándose generación tras generación (analizado en esta tesis). A lo largo de las generaciones se va incorporando mayor complejidad y se asume como evolución. La diferencia se ilustra en estas figuras: 

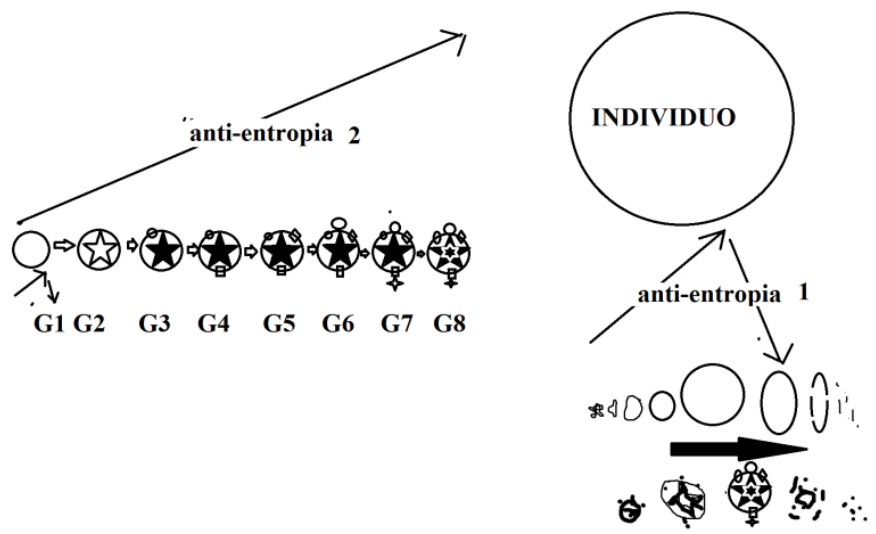

Figura 3. Aumento de Anti-entropía en una reacción en cadena y aumento y declinación de anti-entropía en un individuo. G1, G2... son generación 1, generación 2, etc. Es sobre la primera que versa esta tesis. Fuente: Elaboración propia.

Para que se determine vida deben estar presentes los 2 predicados. No basta uno de ellos.

\begin{tabular}{|c|c|l|c|}
\hline $\begin{array}{c}\text { Procesos } \\
\text { anti-entrópicos }\end{array}$ & $\begin{array}{c}\text { Reacciones } \\
\text { en cadena }\end{array}$ & \multicolumn{1}{|c|}{ Ejemplos } & Dominio \\
\hline si & no & $\begin{array}{l}\text {-cristales } \\
\text {-esculpir una obra de arte }\end{array}$ & NO VIDA \\
\hline no & si & $\begin{array}{l}\text {-fuego } \\
\text {-fusión de uranio }\end{array}$ & VIDA \\
\hline si & si & $\begin{array}{l}\text {-caballos } \\
\text {-humanos } \\
\text {-virus }\end{array}$ & \\
\hline
\end{tabular}

Figura 4. Clasificación de seres naturales en vivos y no vivos. Fuente: Elaboración propia.

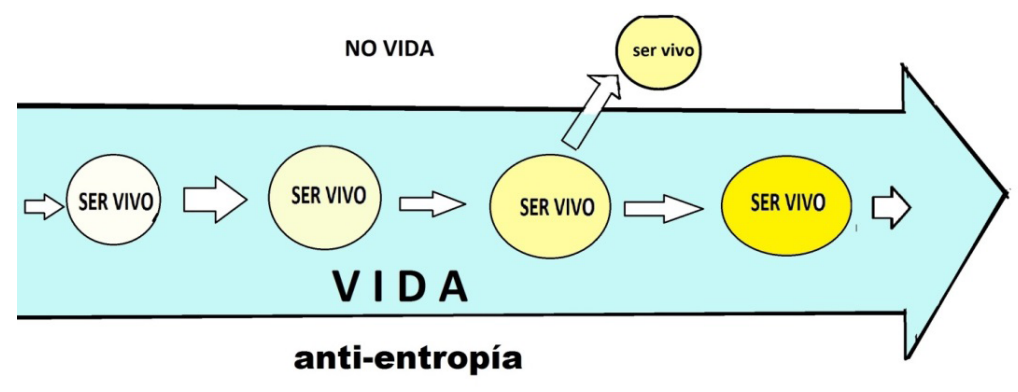

NO VIDA

NO VIDA

Figura 5. La vida no es algo que este en cada ser vivo, sino algo que pasa con ellos. Los organismos participan de la vida. Fuente: Elaboración propia. 


\subsubsection{Darwinismo termodinámico}

¿Cómo se acumula anti-entropía? Sería por siguiente proceso: La reacción en cadena de la vida es imprecisa, origina copias distintas al azar, se genera diversidad, algunos cambios implican mayor efectividad en la auto-multiplicación de la reacción en cadena (anti-entropía). Necesariamente perduran. La evolución en la tierra se entiende como el cambio de la estructura genética de las poblaciones de seres vivos, y se trataría de un caso particular de darwinismo termodinámico, cuyas diferencias con la evolución son:

-No se adquiere adaptación sino se acumula anti-entropía, complejidad útil (orden).

-No tiene como protagonistas seres vivos sino reacciones en cadena, es decir entes abióticos.

-Puede verificarse en una sola generación a diferencia de la evolución.

De este modo se elude el problema del círculo vicioso en la definición usada.

\subsection{Teoremas. Consecuencias de la tesis}

Consideramos que la tesis resuelve el problema de la definición y además que varios problemas teóricos de la biología secundarios, que han permanecido sin solución, que se resuelven al asumir esta definición de vida. La solución a estos problemas son teoremas, pues son inferidos o deducidos de esta sin necesidad de agregar más hipótesis. También aparecen nuevas propiedades de la vida que se infieren de esta definición y que han estado invisibles antes. Son los siguientes:

\subsubsection{Cómo pueden surgir reacciones en cadena que acumulen an- ti-entropía (vida)?}

Las condiciones necesarias son una fuente de energía, sustancias que reaccionen a esa energía multiplicándose y que esas sustancias sean capaces de acumular anti-entropía u orden capaz de hacer más efectiva su auto-multiplicación. En esta tesis la vida empieza cuando la materia es expuesta a la energía y responde a ella auto-multiplicándose y acumulando orden; es interesante contrastar este modelo con las propuestas de Jeremy England, sobre disipación de energía y acumulación de orden e incluso auto-multiplicación en entes abióticos:

when a group of atoms is driven by an external source of energy and surrounded by a heat bath, it will often gradually restructure itself in order to dissipate increasingly more energy. (Wolchover, 2014) 


\subsubsection{La Vida es un fenómeno físico}

Las dos propiedades propuestas para definir “vida” son propiedades físicas, por lo tanto es un problema físico o resuelto en la Física. No hace falta remontar las leyes de la materia y la energía convencionales para explicar la vida. Ni se trata de un epifenómeno o una característica "emergente" misteriosa.

\subsubsection{Los virus son seres vivos, los priones, no}

Los virus son reacciones en cadena que acumula anti-entropía. Un argumento contra la idea de que los virus son vida es que son parásitos que usan un metabolismo ajeno, pero con este argumento todos los animales parásitos no serían vida. Por otro lado el concepto de pertenecer parece más bien un criterio humano devenido del concepto de propiedad privada que proyectamos inapropiadamente sobre entes no humanos.

Los priones no son vida porque al igual que el fuego se reproducen y desarrollan, pero no acumulan orden.

\subsubsection{La Vida empezó en el primer ARN}

Según la tesis, el primer ser vivo en la tierra fue la primera sustancia capaz de ser una reacción en cadena y acumular anti-entropía. Esto fue mucho antes de las primeras células, lo que contradice a Bunge que solo concibe la vida con células. La única sustancia química que se conoce que se forma espontáneamente y es capaz tanto de hacer una reacción en cadena y de acumular anti-entropía es el ácido ribonucleico. Esto coincide con la denominada hipótesis del mundo de ARN y hay evidencia de laboratorio de que esta sustancia es capaz de ser una reacción en cadena y acumular anti-entropía (Cech, 1986 y 1989; Eckland, 1995).

\subsubsection{Como reconocer Vida extraterrestre}

Reconocer vida extraterrestre solo requeriría reconocer que sea una reacción en cadena y que acumule anti-entropía. Para esta no basta el análisis individuos sino las relaciones o sistemas que estos crean. Los sistemas actuales de detección de vida extraterrestre fallan en este enfoque y por ende son infructuosos. $Y$ en general la exobiología carente de una definición científica de vida, parece no buscar vida extraterrestre sino vida terrestre fuera de la Tierra. 


\section{Discusión}

\subsection{Esta definición satisface los estándares de definición científica}

Una definición científica debe satisfacer una lista de requisitos. Ahora analizaremos una por una estas demandas, para determinar si la definición de vida propuesta las satisface.

\subsubsection{Permiten hacer explicaciones, predicciones y retrodicciones}

Esta tesis puede hacer estas 3 cosas:

\begin{tabular}{|l|l|}
\hline Explicaciones & $\begin{array}{l}\text {-Los virus son vida, los priones no. } \\
\text {-La vida tiene 2 propiedades universales y esencia- } \\
\text { les. }\end{array}$ \\
\hline Predicciones & $\begin{array}{l}\text {-Si se halla vida extraterrestre esta será compleja. } \\
\text {-Necesitará fuente de energía pues toda reacción en } \\
\text { cadena la requiere. } \\
\text {-Se multiplicará de algún modo por ser una reacción } \\
\text { en cadena. }\end{array}$ \\
$\begin{array}{l}\text {-Se podrá hallar formas de vida no basadas en el } \\
\text { carbono, incluso sin agua pero nunca sin energía } \\
\text { disponible. } \\
\text {-Cuando las maquinas aprendan a reproducirse y } \\
\text { acumular información independiente de la voluntad } \\
\text { humana serán vida. } \\
\text {-Si hay otros universos con otras conformaciones } \\
\text { de la materia y la energía (Hawking, 2010) la vida } \\
\text { podrá existir en ellos si hay disponible energía y sus- } \\
\text { tancias que acumulen anti-entropía y se automulti- } \\
\text { pliquen. Se refuta así el principio antrópico fuerte } \\
\text { que supone que este universo esta calibrado espe- } \\
\text { cialmente para permitir la vida. }\end{array}$ \\
\hline Retrodicciones \\
$\begin{array}{l}\text { Podemos responder a la pregunta de Maturana: } \\
\text { cué empezó cuando empezó la vida? La respues- } \\
\text { ta es que ciertas reacciones en cadena empezaron a } \\
\text { acumular anti-entropía. }\end{array}$ \\
\hline
\end{tabular}

Figura 6. Implicaciones de esta tesis. Fuente: Elaboración propia.

\subsubsection{Pueden ser descriptivas. Que sirven para describir el significado de un término ya en uso}

En ellas el definiendum, se explica por el definiens, es decir con términos ya definidos que pueden sustituirlo. Es el caso pues hemos definido "vida" (Definiendum) como una reacción en cadena que acumula anti-entropía (Definiens). 


\subsubsection{Se puede decir que son más o menos exactas, o incluso verdaderas o falsas}

Una definición es verdadera cuando hay algo en el mundo que es así y cuando no hay ningún contra-ejemplo. Es el caso.

\subsubsection{Se debe evitar "círculos", que definen un término con ayuda de sí mismo}

El Definiens está en términos físicos completamente independientes del Definiendum.

\subsubsection{Las definiciones son particiones en sentido matemático, clasifica- ciones no-solapantes}

La definición propuesta señala qué procesos son vida y cuáles, no. No existen ejemplos de algo que no sea vida o no-vida. Tampoco hay objetos de transición que pertenezcan a ambos conjuntos. Se refuta así la posición de Bunge sobre una transición gradual entre vida y no vida.

\begin{tabular}{|l|l|}
\hline Pertenecen al conjunto Vida & \multicolumn{1}{|c|}{ No pertenecen al conjunto Vida } \\
\hline Todas las especies terrestres. & $\begin{array}{l}\text { Objetos que no son reacciones en cadena } \\
\text { ni acumulan anti-entropía: todos los ob- } \\
\text { jetos inanimados. }\end{array}$ \\
\hline Virus (adenovirus y retrovirus). & $\begin{array}{l}\text { Reacciones en cadena que no acumulan } \\
\text { anti-entropía: fuego, priones, especies } \\
\text { partenogénicas. }\end{array}$ \\
\hline $\begin{array}{l}\text { Hipotética vida extraterrestre, } \\
\text { artificial o sintética. }\end{array}$ & $\begin{array}{l}\text { Objetos que acumulan anti-entropía pero } \\
\text { no son reacciones en cadena: cristales. }\end{array}$ \\
\hline
\end{tabular}

Figura 7. Pertenencia y no pertenencia al conjunto “vida”. Fuente: Elaboración propia.

Un caso que merece análisis son las especies que no evolucionan (no acumulan anti-entropía). Por ejemplo la lagartija Aspidoscelis rodecki o la planta Bougainvillea spectabilis que se reproducen únicamente por reproducción asexual. Ambas no serían vida. Otro caso es de los individuos estériles como las mulas, célibes u homosexuales. ¿No son vida? pues según la definición, "vida” es un atributo de reacciones en cadena de individuos (generaciones, linajes) no de individuos (fértiles o no) por lo que no tiene sentido preguntárnoslo. 


\subsubsection{En definiciones operacionales el significado de un término cientí- fico indica una operación definida de contrastación}

La operación para identificar "vida" es la siguiente: Se debe poder identificar que se multiplican al absorber energía (reacción en cadena) y que acumulan anti-entropía. Si se encuentran estas dos propiedades hemos identificado vida.

\subsubsection{Una partición es más fina que otra cuando hace todas las distin- ciones que esta y algunas más}

Es el caso.

\begin{tabular}{|l|l|}
\hline $\begin{array}{l}\text { Hace todas las } \\
\text { distinciones }\end{array}$ & $\begin{array}{l}\text { Se reproduce. } \\
\text { Evoluciona. } \\
\text { Es anti-entrópica. }\end{array}$ \\
\hline Algunas más. & $\begin{array}{l}\text { Vida es un proceso no una sustancia u objeto. } \\
\text { Los organismos participan de la vida pero ellos } \\
\text { mismos, individualmente, no tienen las dos } \\
\text { propiedades de esta. } \\
\text { Anti-entropía no es información. } \\
\text { Evolución es un caso especial de "Darwinismo } \\
\text { termodinámico" }\end{array}$ \\
\hline
\end{tabular}

Figura 8. Nuevas propiedades de la vida pueden descubrirse de inferencias hechas partir de este axioma. Fuente: Elaboración propia.

\subsection{Anti-Entropía de la Vida e información}

Mientras el universo adquiere entropía, la vida adquiere anti-entropía. Esta podría considerarse información dado que ese orden o anti-entropía tiene sentido y es opuesto al desorden (Wiener, 1989). Además las fórmulas de anti-entropía termodinámica aplicadas a vida en esta tesis son semejantes a las que usadas en la física convencional y a las fórmulas de Shannon sobre información.

\begin{tabular}{|c|c|}
\hline Anti-entropía & Información \\
\hline anti-entropía $=\mathrm{k} \log (\mathrm{l} / \mathrm{D})$. & $W=K \log m$ \\
\hline
\end{tabular}

Figura 9. Semejanza sintáctica entre anti-entropía e información. Fuente: Elaboración propia.

Pero a pesar de su igualdad sintáctica, la diferencia estaría en su semántica como indica Romero (Mattei, 2015). En otras áreas de la física, como por ejemplo en los trabajos de Stephen Hawking sobre agujeros negros, se usa el concepto de anti-entropía como sinónimo de información. Esto nos podría animar a plantear el siguiente argumento: 
1.-Anti-entropía es información.

2.-Acumulación de anti-entropía es acumulación de información.

3.-Vida es reacción en cadena que acumula anti-entropía.

Por lo tanto:

4.- Vida es una reacción en cadena que acumula información.

Pero no hay seguridad de que la premisa (1) sea verdadera. Esta diferencia semántica puede agravarse en un nuevo terreno como la biología y debemos aceptar que las teorías científicas están inyectadas de semántica y su naturaleza depende de ella. Sin embargo la igualdad matemática muchas veces ha precedido a la unificación de dos fenómenos naturales previamente ajenos uno al otro y que se revelan luego como expresiones particulares de un mismo fenómeno. Por lo que no podemos descartar tajantemente que anti-entropía sea información en biología. Dilucidar este dilema no es crucial para sustentar esta tesis pero si es importante para entender lo que es "vida".

Lo que es orden y lo que no, implica cierta "mirada humana"; es decir un receptor que identifique el mensaje como con sentido, al arrojar diversas letras al azar una combinación "gergergh" es considerada desorden, pero si se forma la palabra "triangulo" se considera orden. La diferencia entre estas dos cosas es que la primera no contiene información y la segunda sí. Pero solo para una mente que decodifica la señal. En la vida la diferencia estribaría en si una conformación de la materia sostiene o no la reacción en cadena. La anti-entropía en la vida sería causas materiales cuyo efecto prolonga la reacción en cadena.

El aumento de orden termodinámico es siempre a expensas de mayor desorden en conjunto, para no violar la segunda ley de termodinámica. Este proceso gasta energía. ¿Y esta de dónde proviene? En cada organismo proviene de la alimentación y la respiración (mecanismos que desordenan) pero ¿qué se desordena en la acumulación de anti-entropía de la vida? Esta tesis propone que proviene de la copia desordenada. Recordemos que la reacción en cadena de la vida debe ser ineficiente, o no produciría copias diferentes, algunas de las cuales aumentarán la anti-entropía pero la mayoría aumentarán la entropía. El desorden en la producción de gametos en la vida terrestre es un caso particular de esto, llamado recombinación genética que por cada combinación útil produce múltiples ineficientes. La generación de desorden entonces es absolutamente necesaria en la acumulación de anti-entropía de la vida.

\section{Conclusiones}

1. La "vida" es una reacción en cadena que acumula anti-entropía, por lo tanto la vida no es el conjunto de seres vivos u organismos sino el conjunto de reacciones en cadena que acumulan anti-entropía. 
2. Vida es diferente de ser vivo.

3. Todas las características intuitivamente atribuidas a la vida pueden inferirse de este axioma.

4. La vida es un proceso físico con dos propiedades físicas y se puede definir en términos abióticos.

5. Los virus son vida, los priones, no.

6. La vida en la Tierra empezó con el ARN.

7. Las especies de reproducción únicamente asexual, no son vida.

8. La anti-entropía de la vida no es información sino causalidad. A pesar de su igualdad sintáctica o matemática, la diferencia es semántica.

9. El proceso por el que se acumulan anti-entropía es "Darwinismo termodinámico" y está en términos abióticos del que la evolución es solo un caso particular.

\section{Referencias bibliográficas}

Aristotle. (2007). On the soul. Consulta el 2 febrero de 2011 translated by J. A. Smith Recuperado de eBooks@Adelaidehttp://ebooks.adelaide.edu.au/a/aristotle/ a8so/index.html

Benner S. R. \& Carrigan M. (2004) Is there a common chemical model for life in the universe? Curr Opin Chem Biol. Dec; 8(6), 672- 689.

Bunge, M. \& Hahner, M. (2000). Fundamentos de Biofilosofía. (1 ${ }^{\text {ra }}$ ed). México. Siglo 21 editores.

Bunge. Mario (s/f) Conferencia dictada en 1980 por en la Facultad de Estudios Generales de la Universidad de Puerto Rico. Recuperado de https://www.youtube.com/watch?v=v7Qfp 88Hmz8

Cleland,C et al. (2010). Does 'life' have a definition? The Nature of Life

Classical and Contemporary Perspectives from Philosophy and Science. University of Colorado Christopher F. Chyba, Princeton University, 326- 339

Cech, T. R. (1986). RNA as an enzyme. Scientific American. Nov;255(5), 64-75.

- (1989). RNA as an enzyme. Biochem Int. 1989 Jan;18(1), 7- 14.

Darwin C. (1921). El Origen De Las Especies Por Medio De La Selección Natural. Madrid

Ed Regis. (2009). What is life? Investigating the nature of life in the age of synthetic biology. New York. OXFORD University press.

Eckland E. H., Szostak J. W. \& Bartel D. P. (1995). Structurally complex and highly active RNA ligases Derived from Random RNA Sequences. Science. Jul 21 v $269,364-370$. 
Emmeche (1998). Defining life as a semiotic phenomenon, Cybernetics \& Human Knowing 5 (1), 3- 17.

Hawking, S \& Mlodinow, L. (2010). El gran Diseño. Barcelona. Crítica.

Hempel, C. (1987), Filosofía de la Ciencia Natural. Madrid. Alianza Ed.

Mattei, G. (2015) Entrevista A Gustavo Romero: Un Anaximandro Del Siglo Xxi NEX CIENCIA Buenos Aires. Recuperado de: http://nexciencia.exactas.uba. ar/un-anaximandro-del-siglo-xxi

Maturana, H. \& Varela, F. J. (1973). De máquinas y seres vivos: una teoría sobre la organización biológica. Santiago de Chile. Editorial Universitaria S. A.

Mosterin,J. (2000). Conceptos y Teorías en la Ciencia ( $3^{\mathrm{a}}$ ed) Madrid, Alianza Editorial

Rinaldi, A. (2007). Space life holds its breath. Pressured by scepticism, budget cuts and the need to prove itself, astrobiology is coming to a crossroads $E M B O$ Science and Society Analysis Rep. May; 8(5), 436- 440.

Schrodinger, E. (1945). What is life? The Physical aspect of the living cell.Cambridge. UniversityPress.

Smith K. (2016) Life is hard: countering definitional pessimism concerning the definition of life. The history and philosophy of the Origin of Life. International Journal of Astrobiology. Volume 15, Issue 4 October, 277- 289

Tirard, S., Morange, M., \& Lazcano. (2010) The Definition of Life: A Brief History of an Elusive Scientific Endeavor ASTROBIOLOGY Volume 10, Number 10.

Wiener, N. (1989) The Human Use OfHuman Beings London. Cybernetics And Society Free Association Books.

Wolchover, N. (2014). A New Physics Theory of Life. Quanta Magazine January 22. 